\section{Antenatal screening for Down's syndrome}

EDrToR,-Nicholas J Wald and colleagues' demonstration project' implies that there is nothing left to prove with regard to the "triple test" screening of pregnant women for Down's syndrome, and that all that remains is for the test to be introduced on a national level immediately. This is a premise I and others feel unhappy about, as recent correspondence has shown. ${ }^{2}$

Wald and colleagues report the results of screening 12603 women with the triple test, achieving a detection rate of $48 \%$ in that population. It is true that the numbers are small $(12 / 25)$, but this is considerably below the $58 \%$ previously suggested. The paper does not refer at all to the $26 \%$ of women not screened. If the 12603 women discussed in the paper were the $74 \%$ who had the blood test, the total population under study therefore comprised 17031 women. Because we have no information about the demographic characteristics of the other 4428 women, or the outcomes of their pregnancies, I can only assume that the rate of Down's syndrome in their pregnancies was the same as in the screened population. Thus, the conclusion must be that some 34 pregnancies in the study population were affected with Down's syndrome. This figure reduces the detection rate for this pregnant population as a whole to $35.3 \%$ and the known prevention of Down's births (presumably the desired outcome) to $26.5 \%$. Additionally, a two way table for the screened population gives the triple test a positive predictive value of only $2 \cdot 3 \%$, a figure well below that required for any method of screening.

On this basis, it must again be asked whether the wholesale introduction of triple test screening is either appropriate or effective. Wald and colleagues' paper certainly does not show, despite its claims, that the incidence of Down's births will be reduced much further in practice. It is probable that the psychological costs of this programme to pregnant women will be enormous': 17031 had to consider the test, 12603 had to wait for results, and 514 undergo amniocentesis. We are not told the miscarriage rate. It also seems from recent correspondence ${ }^{67}$ that the costings used by the authors for their cost effectiveness analysis are probably an underestimate. As there are costs incurred through counselling for all women, the cost effectiveness analysis looks even less favourable when the whole population, rather than only those who are screened, is considered.

Department of Public Health Medicine,

South West Surrey Health Authority,

Guildford,

Surrey GU2 5LX

1 Wald NJ, Kennard A, Densem JW, Cuckle HS, Chard T, Butle L. Antenatal maternal serum screening for Down's syndrome: results of a demonstration project. BMF 1992;305:391-4. (15 August.)

\section{Advice to authors}

Priority will be given to letters that are less than 400 words long and are typed with double spacing. All authors should sign the letter. Please enclose a stamped addressed envelope for acknowledgment.
2 Fleming C, Goldie DJ. Risk of Down's syndrome and amniocentesis rate. $B M \mathcal{F}^{1992 ; 304: 252}$.

3 Keatinge RM, Williams ES. Screening for Down's syndrome. BMF 1991;303:1063.

4 Wald NJ, Cuckle HS, Densem JW, Kennard A, Smith D Maternal serum screening for Down's syndrome: the effect of routine ultrasound scan determination of gestational age and adjustment for maternal weight. Br f Obstet Gynaecol 1991;99: 144-9.

5 Marteau T. Reducing the psychological costs. BMF 1990;303 26-8.

6 Keatinge RM, Williams ES. Prenatal screening for Down's syndrome. BMF 1991;303:54

7 Davies T, Kha OS. Prenatal screening for Down's syndrome BMf 1991;303:312

EdITOR,-Nicholas J Wald and colleagues conclude that antenatal maternal serum screening is cost effective and that the NHS should ensure its availability throughout Britain.' Their results do not support this contention. Screening detected only $12(48 \%)$ of the 25 affected pregnancies and led to abortion in only $9(36 \%)$. Even less impressive is the detection rate of $39 \%$ in women aged under 37 , in whom most affected pregnancies occur. For each woman with a "positive" screening result the odds of having an affected fetus were 1 in 43 , and for each woman having amniocentesis the odds were 1 in 29 . The positive predictive value is $1.6 \%$ before and $2 \cdot 3 \%$ after revision of dates by ultrasound examination. Would such results be acceptable for other screening programmes, such as mammography followed by biopsy for breast cancer?

The claim that screening is cost effective is based solely on an estimate of financial costs. There is no mention of the costs to women in terms of repeated clinic visits, morbidity and miscarriage after amniocentesis, and anxiety while waiting several weeks from the initial screening to receive the results of karyotyping. There is no confirmation that all aborted fetuses had Down's syndrome. There is also no discussion of the finding that the level of risk had only a small influence on the decision of $25 \%$ of women with a "positive" screening result not to have amniocentesis.

Finally, the authors write that "the predicted results are a better guide to expected performance than the observed results in this dataset would indicate." The logical conclusion of such a statement is that the results of research should be ignored if they fail to come up to the authors' expectations.

Department of Public Health Medicine,

West Berkshire Health Authority,

Reading RG3 4EJ

1 Wald NJ, Kennard A, Densem JW, Cuckle HS, Chard T, Butler L. Antenatal maternal screening for Down's syndrome: results L. Antenatal maternal screening for Down's syndrome: results
of a demonstration project. BMF 1992;305:391-4. (15 August.)

EDITOR,-International leadership in prenatal screening resides in Britain; accordingly British public health policy has positively influenced other nations. Against that background, Nicholas J Wald and colleagues call for the establishment of British policy to achieve "the avoidance of handicap . . . to families." When the work of some scientists and medical professors concludes with nationally directive pronouncements-for example, "the NHS should ensure that antenata maternal serum screening for Down's syndrome is available throughout Britain," others may wish to consider whether the underlying data reasonably support the conclusions. We find Wald and colleagues' national expectations to be costly, the data unconvincing, and the conclusions premature.

We urge that more information be obtained because the costs per affected case are underestimated; the utility of unconjugated oestriol as a third marker is not reported; Wald and colleagues' reported detection rates ( $48 \%$ overall, $39 \%$ for the screening population under 37 years of age) are lower than detection rates using other assay protocols; and independent reports on false positive rates and detection efficiency should be obtained from other screening centres.

Wald and colleagues use $61 \%$ detection in estimating costs rather than their published detection rate of $48 \%$. At $48 \%$ (even without accounting for the cost of maternal serum $\alpha$ fetoprotein measurements) the public sector direct cost per detected affected pregnancy is $£ 36256$, not $£ 28500$ (assuming 100\% uptake of amniocentesis and $100 \%$ termination of affected pregnancies). The cost increases to $£ 48780$ with $75 \%$ uptake of amniocentesis and $90 \%$ termination of affected pregnancies. Considering private sector triple test costs at $£ 60$ per test ${ }^{2}$ and an incidence of 1.05 Down's syndrome cases per 1000 live births in Britain, ${ }^{3}$ the costs increase to $£ 134929$ and $£ 174511$ respectively.

The authors omit showing how using unconjugated oestriol in an assay protocol affects detection and false positive rates despite published studies showing negative impact. ${ }^{4}$ They should responsibly show that each biochemical marker improves on Down's syndrome screening detection rates.

Reported detection rates with other assay proto cols are $89 \%,{ }^{5} 80 \%,{ }^{6} 78 \%,{ }^{7} 75 \%$ (R.G Ryall, personal communication). Laboratories currently using the triple test and the " $\alpha$ lpha" software should publish their independently observed data on detection and false positive rates so that doctors and scientists may accurately gauge effectiveness and give the NHS a clearer statement of the facts.

VINCENT J MACRI REBECCA CLARK

NTD Laboratories,

Carle Place, New York 11514-2137

USA

1 Wald NJ, Kennard A, Densem JW, Cuckle HS, Chard T, Butle L. Antenatal maternal serum screening for Down's syndrome: results of a demonstration project. BMF 1992;305:391-4. (15 August.)

2 Ballantyne A. Mother sues over lack of Down's test. Sunday Times 1992 August 23:4.

Sheldon TA, Simpson J. Appraisal of a new scheme for prenatal screening for Down's syndrome. BMF 1991;302:1133-6.

4 Macri JN, Cook EJ, Kasturi RV, Krantz DA. Prenatal screening for Down's syndrome. BMF 1 1991;303:468.

for Down's syndrome. BMf 1991;303:468.
5 Spencer K, Carpenter P. Risk of Down's syndrome and amnioSpencer K, Carpenter P. Risk of Down's synd
centesis. BMf 1992;304:640-1. (7 March.)

6 Macri JN, Kasturi RV, Krantz DA, Cook EJ, Moore ND, Young $\mathrm{JA}$, et al. Maternal serum Down syndrome screening: free $\beta$ $\mathrm{JA}$, et al. Maternal serum Down syndrome screening: free $\beta$ protein is a more effective marker than human
gonadotropin. Am $\mathcal{F}$ Obstet Gynecol 1990;163:1248-53.

7 gonadotropin. Am $\mathcal{F}$ Obstet Gynecol 1990;163:1248-53. free beta human choriogonadotropin. Ann Clin Biochem 1992, 29:349-50.

EDITOR,-The results from the study by Nicholas $\mathrm{J}$ Wald and colleagues ${ }^{1}$ raise several important issues.

The implied conclusion that this form of Down's syndrome screening is more "effective" than screening by maternal age alone is debatable, as the findings could have occurred by chance. In the 
whole screened population the number of babies with Down's syndrome was 25 . With Wald and colleagues' screening test, the number of Down's syndrome babies detected was 12 . With screening by maternal age $\geqslant 37$ years alone, the number detected could have been 7 out of 25 . These proportions are not significantly different (Fisher's exact test $p=0 \cdot 24$; odds ratio $2 \cdot 37 ; 95 \%$ confidence interval 0.73 to 7.68 ). Even with the different uptake of amniocentesis in the two groups-that is, $75 \%$ for all ages and $63 \%$ for those $\geqslant 37$ yearsthere was still no significant difference in the result $(p=0 \cdot 2$; odds ratio $2 \cdot 95(0 \cdot 77$ to $11 \cdot 3))$.

Only $4.9 \%$ of women were aged $\geqslant 37$ years; the confidential enquiries into maternal deaths in the United Kingdom 1985-7 reported that $8 \%$ of pregnant women were over $35^{2}$ and in our hospital in 1991 the proportion $\geqslant 37$ years was $9 \cdot 2 \%$. This proportion is likely to rise as women delay their families for personal and financial reasons, and as this proportion rises the detection rates from the triple test and from maternal age alone will become even more similar.

In any particular district the cost of introducing this programme will depend on the proportion of women $\geqslant 37$ years; in addition, many authorities (including our own) have now abandoned $\alpha$ fetoprotein testing, relying for neural tube defect screening on ultrasonography alone, and the cost of reintroducing this test would need to be accounted for in the calculations.

ANDREW C J ALLMAN

PETER J DANIELIAN PHILIP J STEER

Academic Department of Obstetrics and Gynaecology,

Charing Cross and Westminister Medical School

West London Hospital,

London W6 7DQ

1 Wald NJ, Kennard A, Densem JW, Cuckle HS, Chard T, Butler L. Antenatal maternal serum screening for Down's syndrome results of a demonstration project. BMF 1992;305:391-4. (15 August.)

Department of Health, Welsh Office, Scottish Home and Health Department. Report on the Confidential Enquiries into Maternal deaths in the United Kingdom 1985-1987. London: HMSO 1991:18.

EDITOR,-Nicholas J Wald and colleagues describe a demonstration project for Down's syndrome screening in which the detection rate achieved was $48 \%(12 / 25$ cases $)$ at a $4 \cdot 1 \%$ false positive rate. ${ }^{1}$ They used three biochemical tests ( $\alpha$ fetoprotein, total human chorionic gonadotropin, and unconjugated oestriol) along with maternal age in the so called triple test.

Our screening programme has used only $\alpha$ fetoprotein (and maternal age) in combination with the marker free $\beta$ human chorionic gonadotrophin. In our large retrospective study free $\beta$ human chorionic gonadotrophin was shown to be the biochemical marker with the greatest predictive value for Down's syndrome. ${ }^{2}$ Studies with 90 cases of Down's syndrome and 2862 unaffected controls showed that the combination of $\alpha$ fetoprotein and free $\beta$ human chorionic gonadotrophin detected more cases of Down's syndrome than did the triple test approach. This study confirmed previous findings in which detection rates of $75-80 \%$ were achieved in the early gestational period (14-16 weeks). ${ }^{3.5}$

In prospective studies using the free $\beta$ protocol we have achieved detection rates for Down's syndrome of $73 \%(11 / 15)$ with a $5 \cdot 5 \%$ false positive rate. Unlike Wald et al's study, which detected only $20 \%$ more cases than would have been detected by a policy of screening according to advanced maternal age, our programme detected an additional $53 \%$ of cases. These results, in which $\alpha$ fetoprotein and free $\beta$ human chorionic gonadotrophin detect more cases of Down's syndrome in younger women, confirmed observations in our retrospective study, in which this combination detected $100 \%$ more cases in women under 30 than did the triple test.
Observations that concentrations of free $\beta$ human chorionic gonadotrophin are raised in the first trimester in Down's syndrome pregnancies ${ }^{6}$ add further weight to our argument that free $\beta$ human chorionic gonadotrophin is the marker of choice for Down's syndrome screening. The benefit of additional tests such as unconjugated oestriol is at best unproved and at worst widens the error in the risk estimate, ${ }^{78}$ may add to the false positive rate,${ }^{29}{ }^{10}$ and adds to the laboratory screening costs.

The scientific and medical community is best served by a balanced argument of the facts, rather than the exaggerated media reports of recent publications. Health authorities should be aware of the cost implications of making decisions in which suboptimal screening programmes are suggested. The general public and patients are not best served by an oversimplification of the facts that in turn grab headlines. Fortunately the scientific and medical community is capable of seeing through the "hype" and is able to make its own balanced judgments. At least as many laboratories in the United Kingdom are now using the free $\beta$ human chorionic gonadotrophin protocol as are offering the triple test. The benefit of an increased detection rate and improved screening efficiency with the use of technologically advanced analytical procedures ${ }^{11}$ will ensure that those benefits become available to all health authorities.

Clinical Biochemistry Department,

Oldchurch Hospital,

Romford,

Essex RM7 OBE

1 Wald NJ, Kennard A, Densem JW, Cuckle HS, Chaud T, Butler L. Antenatal maternal serum screening for Down's syndrome: results of a demonstration project. BMJ 1992; 305:391-4. (15 August.)

2 Spencer K, Coombes EJ, Mallard AS, Milford Ward A. Free beta human choriogonadotropin in Down's syndrome screening: a multicentre study of its role compared with other ing: a multicentre study of its role compared

3 Macri JN, Kasturi RV, Krantz DA, Cook EJ, Moore ND, Young JA, et al. Maternal serum Down syndrome screening free beta protein is a more effective marker than human chorionic gonadotropin. Am f Obstet Gynecol 1990;163 1248-53.

4 Spencer K. Evaluation of an assay of the free beta subunit of choriogonadotropin and its potential value in screening fo Down's syndrome. Clin Chem 1991;37:809-14.

5 Spencer K, Macri JN. Early detection of Down syndrome usin free beta human choriogonadotropin. Ann Clin Biochen 1992;29:349-50

6 Spencer K, Macri JN, Aitken DA, Connor JM. Free Beta hCG as first trimester marker for fetal trisomy. Lancet 1992;339: 1480 .

7 Spencer K, Carpenter P. Estimating risk of Down's syndrome. BMF 1991;302:1536-7.

8 Reynolds TM. Practical problems in Down syndrome screening: What should we do about gestational dating? What is the effect of assay precision on risk factors? Commun Lab Med effect of ass

9 Macri JN, Kasturi RV, Cook EJ, Krantz DA. Prenatal screening for Down's syndrome. BMf 1991;303:468.

10 Crossley JA, Aitken DA, Connor JM. Second trimester unconjugated oestriol levels in maternal serum from chromosomally abnormal pregnancies using an optimised assay. $\mathcal{F}$ Med Genet 1991;28:569-70

11 Macri JN, Spencer K, Anderson R. Dual analyte immunoassay -a new approach to neural tube defect and Down's syndrom screening. Ann Clin Biochem 1992;29:390-6.

EDITOR,-We have carried out with others similar study to that by Nicholas $\mathrm{J}$ Wald and colleagues, ${ }^{1}$ offering screening for Down's syndrome to 10000 pregnant women in south Wales. This was submitted to the Welsh Office in February 1992. We would like to comment on the findings of Wald and colleagues.

In the population studied by Wald and colleagues $5 \cdot 5 \%$ of women were aged over 37 years; in these women the detection rate was $71 \%$. The detection rate in younger women was only $39 \%$. This is important because the overall detection rate in a predominantly younger population would be decreased. Our population has only $2.8 \%$ of pregnancies in women aged over 37

The initial screen positive rate found by Wald and colleagues was $5 \cdot 7 \%$, whereas our study had an initial screen positive rate of $3 \cdot 5 \%$. They used the triple test ( $\alpha$ fetoprotein, human chorionic gonadotrophin, and unconjugated oestriol, whereas we used a double test ( $\alpha$ fetoprotein and human chorionic gonadotrophin). The detection rates in the two studies were almost identical: Wald and colleagues found $48 \%$ and we found $50 \%$.

Our detection rate was effectively identical to that of Wald and colleagues but we had an initial screen positive rate that was $40 \%$ lower. We used only two analytes, consistent with reports that using unconjugated oestriol in screening is of minimal benefit, ${ }^{23}$ increases the false positive rate, ${ }^{4}$ and greatly increases the imprecision of risk estimates.

Thus, although Wald and colleagues' study shows that Down's syndrome screening is a useful addition to antenatal care, it does not show that the triple test has any advantages over a double test.

Department of Obstetrics and Gynaecology,

University Hospital of Wales College of Medicine

Cardiff

Department of Chemical Pathology,

Royal Gwent Hospital

Newport, Gwent NP9 2UB

1 Wald N, Kennard A, Densem J, Cuckle HS, Chard T, Butler L. Antenatal maternal serum screening for Down's syndrome: results of a demonstration project. BMJ 1992;305:391-4. (15 August.)

2 Spencer K, Coombes E, Mallard A, Milford-Ward A. Unconjugated estriol has no place in second trimester Down screening.
. gated estriol has no place
Clin Chem 1992;38:956.

3 Macri J, Kasturi R, Krantz D, Cook E, Larsen J. Measuremen of unconjugated estriol by ELISA fails to show an association with Down syndrome. Am J Obstet Gynecol 1990;162:1634-5.

4 Macri J, Kasturi R, Cook E, Krantz D. Prenatal screening for Down's syndrome. $B M F$ 1991;303:408.

5 Reynolds T. Practical problems in Down syndrome screening. Commun Lab Med 1992;1:31-8.

EDITOR,-Although we congratulate Nicholas J Wald and colleagues on their demonstration project, ${ }^{1}$ three points deserve comment.

Firstly, we are surprised that $25 \%$ (129/526) of the women who proved positive on screening subsequently declined the offer of amniocentesis despite access to individual counselling. We speculate that many of these women did not understand the nature of the initial screening test and that the knowledge that they were at increased risk of having a Down's syndrome baby could have been a source of stress for the remainder of their pregnancy.

Secondly, the authors discuss the advantage of performing a dating ultrasound examination on all women at the time of screening to avoid the need to later reassess positive results after a revision of gestational age. Another advantage is in avoiding possible costly litigation by women with false negative results, where it might be argued that dating by clinical methods alone is negligent. Had a scan been performed, the screening test would have been interpreted differently and amniocentesis offered.

Finally, to assess the population impact of the screening programme it is necessary to know how many Down's syndrome babies were born to the $26 \%$ of mothers who declined screening.

PAUL BINGHAM

Isle of Wight Health Commission,

Newport, Isle of Wight PO30 1JW

Southampton and South West Hants Health

PETER OLD

Authority,

Southampton SO9 $4 \mathrm{WQ}$

1 Wald NJ, Kennard A, Densem JW, Cuckle HS, Chard T, Butler L. Antenatal maternal serum screening for Down' syndrome: results of a demonstration project. BMf 1992;305: 391-4. (15 August.)

EDITOR,-Nicholas J Wald and colleagues claim that antenatal serum screening for Down's 